\title{
CATALOG BASED ON THE NURSING INTERNATIONAL CLASSIFICATION IN HEART FAILURE: A DESCRIPTIVE STUDY
}

\author{
Sílvia Maria de Sá Basílio Lins ${ }^{1}$, Fátima Helena do Espírito Santo², Patrícia dos \\ Santos Claro Fuly ${ }^{3}$
}

\author{
1,2,3 Professional Masters in Assistive Nursing by the Aurora Afonso Costa \\ Nursing School of Universidade Federal Fluminense, RJ, Brazil.
}

\begin{abstract}
Aim:This is a study of quantitative approach, of a descriptive nature, to be developed in the coronary unit of a College hospital placed in the city of Niterói, Brazil. It will be used both the Theory of Basic Human Needs and the International Classification for Nursing Practice - ICNP. As a general goal, we expect: (1) to elaborate an ICNP catalogue for hospitalized patients with diagnosed heart failure. Other specific goals comprehend: (1) to raise the phenomenon of nursing practices placed on the medical records of the patients with heart failure during their period of hospitalization, (2) to elaborate, based on the nursing diagnoses, declarations of the results generated. The ethical aspects will be preserved according to the Resolution 196/96.

Descriptors: Nursing Diagnostics; Nursing Procedures; Heart Failure.
\end{abstract}

\section{CONTEXTUALIZATION OF THE TOPIC AND THE PROBLEMATIC OF THE RESEARCH}

The nursing procedures (NP) allow identifying individually the needs of health-illness of each patient and the appropriate nursing care. The NP is regulated by the Resolution $358 / 2009$ of the Brazilian National Council of Nursing (COFEN, in Portuguese), which describes the steps of the process and determines that the same has to be based on a nursing theory ${ }^{(1)}$. For its application, however, besides the theory it is necessary that the use of a unified language that consent to the communication of the nursing team from different cultures and many clinics. The International Classification for Nursing Practice (ICNP) arrived from a world desire of nurses willing for a combined language. Its most updated printed version (ICNP 1.0) has seven axes - Focus, Judgment, Means, Action, Time, Place and Client - which allow the creation of declarations of the diagnosis, interventions and results from nursing practices. These declarations, moreover, can help to develop ICNP catalogues, which picture the application of the $\mathrm{NP}^{(2)}$. The Heart Failure 
(HF) is a complex syndrome, with prevalence in the world that goes from $1 \%$ to $2 \%$ of the population, then being considered a chronic and progressive pathology with high levels of hospitalization, therefore presenting itself as a priority to the creation of an ICNP catalogue ${ }^{(3)}$. Despite the vast literature published in Brazil about NP, it is not a reality in many hospitals, including the hospital where the research will be taken. Because of that, this study has great relevance to the professional practice, as much as for the teaching and learning. It can even contribute to the progress of nursing while a profession and a science in construction, and also proportionate an individual nursing care, more adapted to the patient.

\section{OBJECTIVES}

General: To elaborate an INCP Catalogue for the patients hospitalized with Heart Failure. Specific: To raise the nursing phenomenon placed on medical records of patients with heart failure, during their time of hospitalization. To identify the nursing interventions applied to the patients with heart failure. To formulate, based on the nursing diagnostics, declarations for the expected results.

\section{METHODOLOGY}

This study has a quantitative approach, of a descriptive and transversal nature with a data collection made from medical records. It will be taken from the coronary unit of a school hospital of the city of Niterói, Brazil. The population consists of the patients with heart failure that were hospitalized in the coronary unit in the period of January to December of 2010. A preliminary survey of the register books of the referred unit identified a total of 21 patients admitted with the diagnosis of heart failure and, because there are short, limited number of patients, it was decided to include all of them in the data collection. There will be analyzed the registers about the first five days of hospitalization, both the daytime and the nighttime registers made by doctors and nurses. There will be a documental analysis in the medical records of the patients with heart failure through a data collection instrument made by the researchers, on which will

Online braz. J. nurs. (Online); 10(2) abr-ago. 2011. 
be brought the clinical manifestations that characterize nursing problems or their potentiality, as well as the nursing actions described by the nurses. These problems will be transformed in nursing diagnoses using the ICNP. The data will be submitted to a simple statistical treatment to verify the representation of the same to the patients with heart failure. The diagnoses which present more than $50 \%$ will be included in the catalogue will be included in the catalogue and its interventions will be described based on the bibliographical research. This project was submitted to the Ethics Committee, as determined by the CONEP through the Resolution 196/96, which deals with the research involving human beings, than approved on $17 /$ December/2010 by the protocol number 0238.0.258.000-10.

\section{REFERENCES}

1. Conselho Federal de Enfermagem (BR). Resolução n 358/2009 [site] 2011; [Ip.]. [citado 01 mai 2011]. Disponível em: http://site.portalcofen.gov.br/node/4384

2. Trigueiro EV, Lima MC, Araújo RTM, Nóbrega MML, Garcia TR. Theoretical definitions of terms attributed to nursing phenomena identified in a school hospital. A systematic review. Online Braz J Nurs 2007, 6(0). Retirado em 09-11-2010, de http://www.objnursing.uff.br//index.php/import1/article/view/630/148

3. Quilici AP, et al. Enfermagem em Cardiologia. São Paulo: Editora Atheneu, 2009.

\section{Project Data}

Dissertation Project for the Professional Masters Program in Assistive Nursing.

\section{Financial Support to the Research}

Regional Nursing Council - CRN/RJ

\section{Ethics in Research Committee Approval}

Aproved in the Ethics in Research Committee of the Antônio Pedro College Hospital (CEPHUAP) of the Universidade Federal Fluminense in 17/December/2010, protocol \#0238.0.258.000-10

\section{Address for correspondence}

Rua Bento Lisboa, 120, bl. 2, apt. 1110

Online braz. J. nurs. (Online); 10(2) abr-ago. 2011. 
Rio de Janeiro, RJ, BRAZIL

22221-011

Online braz. J. nurs. (Online); 10(2) abr-ago. 2011. 